\title{
El pasado nacional (re)interpretado en dos novelas mexicanas: Texas de Carmen Boullosa y Un sueño de Bernardo Reyes de Ignacio Solares.
}

\author{
The national past (re) interpreted in two Mexican novels: Texas by \\ Carmen Boullosa and Un sueño de Bernardo Reyes by Ignacio \\ Solares.
}

Esta obra está bajo una Licencia Creative Commons Atribución 4.0 Internacional. DOI: $\underline{10.32870 / \text { sincronia.axxiii.n75.14a19 }}$

\author{
Diana Sofía Sánchez Hernández \\ Departamento de Letras \\ Universidad de Guadalajara \\ mtradianassh@gmail.com \\ (MÉXICO)
}

Recibido: 03/09/2018

Revisado: $22 / 10 / 2018$

Aprobado: 16/11/2018

\section{RESUMEN}

El presente artículo analiza la manera como Texas de Carmen Boullosa y Un sueño de Bernardo Reyes de Ignacio Solares, abordan el pasado nacional para hablar de problemáticas actuales. En nuestra lectura, ambas novelas mexicanas remarcan heroicidades y valores éticos y morales en torno a sus protagonistas. La construcción del pasado, sin embargo, elude el trazo lineal y progresivo del relato histórico convencional para aportar una composición fragmentaria y movediza que coloca en diálogo la fantasía, el tiempo onírico, la cultura popular, los recuerdos e historias individuales y aquellas experiencias colectivas. La perspectiva teórica que apoya nuestro análisis oscila entre la visión de la poética del texto y los estudios culturales (Alemania). Estos últimos remarcan a la literatura como un medio para la cultura del recuerdo, pues la ficción literaria hace posible retomar, reinventar y/o 
replantear tanto los imaginarios colectivos vigentes como la manera en que las sociedades entienden y representan los tiempos presente, pasado y futur.

Palabras clave: Literatura mexicana contemporánea. Novela histórica fragmentaria. Neocolonización. Memoria y escritura.

\section{ABSTRACT}

This article focus on two mexican novels: Texas by Carmen Boullosa and Un sueño de Bernardo Reyes by Ignacio Solares. Both writers, Boullosa and Solares, talk about the national past to discuss contemporary social and political issues. We suggest that this mexican novels remark ethical and moral values related to the construction of main characters to underline unexistent heroicism and certain values in present. Also, both novels, Texas and Un sueño... combine orality, popular culture and fantasy with official history to underline the problematic border between individual and collective memory. Our conceptual framework is supported by poetic and cultural studies (Germany). This theoretical perspective remarks literature as a medium of cultural memory because literature (re)write, (re)interpret and can reinvent our current collective imaginary. Also, literature deals with the manners that society understand and represent present, past and future.

Keywords: Current Mexican Literature. Fragmentary Historical Novel. Neocolonialism. Memory and creative writing.

La literatura tiene un papel relevante en la cultura del recuerdo por su cualidad de construir universos de lo posible o realidades alternas. Es capaz de incluir datos no corroborados, reflexionar sobre el concepto de memoria, replantear y cuestionar ciertas versiones del pasado e, incluso, aportar nuevos imaginarios (nuevas experiencias del recuerdo) o, en palabras de Astrid Erll (2012, p.204), "nuevas ofertas de sentido". La experiencia vital que ofrece la literatura comunica las 
formas en que cada época una sociedad se entiende a sí misma, entiende su realidad presente y se proyecta en el futuro; es decir, la literatura nos permite analizar cómo las colectividades comprenden, representan y se relacionan con el tiempo. La novela histórica es un género que se ha destacado como el medio idóneo para exponer y analizar estas problemáticas vinculadas con la representación del pasado. Sin embargo, en México, después de ocupar un lugar protagónico en el último tercio de los años noventa, en el siglo XXI cobró popularidad un nuevo tipo de discurso que se ha insertado en lo que genéricamente se denomina "narcocultura". Las novelas en torno a la figura del narcotraficante o a sus implícitas relaciones con la política mexicana dieron mayor visibilidad a autores como Élmer Mendoza, Yuri Herrera, Julián Herbert, Juan Pablo Villalobos, entre otros. Incluso, a pesar de su heterogeneidad, las obras de los escritores mencionados se presentan como "narconovelas" por parte de la industria editorial. La novela histórica aparece, discreta, en las novedades.

En este panorama, llama la atención que el siglo XIX y los acontecimientos del incipiente siglo $\mathrm{XX}$, destaquen como épocas novelables para la ficción literaria actual. En el presente trabajo analizaremos dos obras que fueron publicadas en el mismo año: Texas. La Gran Ladronería en el Lejano Norte (2013) de Carmen Boullosa, que retoma la historia de Juan Nepomuceno Cortina, un personaje olvidado de la cultura popular del norte; y la novela Un sueño de Bernardo Reyes (2013), de Ignacio Solares, que rescata del panteón de los villanos al general y gobernador de Nuevo León, Bernardo Reyes. Lejos de hacer una comparación entre ambas novelas, pretendemos analizar la composición de cada una para conseguir dos propósitos: uno, esclarecer por qué la historia de México mantiene su atractivo frente a un contexto de violencia en el que predominan otros tópicos del tiempo contemporáneo (verbigracia, el narcotráfico); y dos, tomaremos como un eje de reflexión el problema de la memoria y su representación como un medio de acceso al pasado y una forma de conocimiento. La intención de evadir el análisis comparativo exige que abordemos cada novela en su singularidad, por lo que revisaremos primero la obra de Carmen Boullosa para continuar con el texto de Ignacio Solares. 


\section{Juan Nepomuceno Cortina, personaje de leyenda}

Carmen Boullosa, después de la publicación de varias novelas en las que destacan la transtextualidad, la metaficción y la tradición literaria como ejes principales de su narrativa, en Texas. La Gran Ladronería en el Lejano Norte $(2013)^{1}$ la autora regresa a los temas de corte histórico. En contraste con sus novelas históricas previas, como en Cielos de la Tierra (1994) o en Las paredes hablan (2012), en las que condensa varios siglos del pasado nacional, Texas se ubica en un tiempo histórico concreto: 1859, año de la primera rebelión mexicana contra los norteamericanos encabezada por Juan Nepomuceno Cortina (1824-1874) y apoyado por un grupo clandestino autodenominado "Las Águilas", según la propia novela.

El relato de Texas se ubica en las ciudades de Bruneville (Texas) y Matasánchez (México), dos lugares de tránsito cotidiano que, por cuestiones políticas, pertenecerán súbitamente a dos países de rivalidad tanto política como económica. ${ }^{2}$ En este sentido, Texas explora el nacimiento forzado de una frontera geográfica (entendida en la novela como una nueva colonización de México) y su influencia en la caótica y compleja construcción de nuevos imaginarios, nuevas relaciones de sus habitantes con el espacio, con los otros, con la autoridad y consigo mismos. La autora reconoce en este microcosmos un posible origen de los prejuicios negativos en torno a la noción de "mexicanidad" y la experiencia del "ser mexicano" frente a la hegemonía -también creada en este momento- del norteamericano. La construcción de estos nuevos imaginarios atraviesa tanto la distribución espacial, donde los mexicanos de pronto no sólo cambian de nacionalidad sino también sufren la reducción de sus propiedades; como las maneras de usar el lenguaje y su tensión con

\footnotetext{
${ }^{1}$ En el presente trabajo se consultó la edición de Alfaguara publicada en 2013. Las páginas se pondrán entre paréntesis.

2 Antes del tratado de 1848, en el que México pierde la mitad de su territorio, la división política que las delimitaba era difusa y, por lo tanto, el río Bravo -su frontera natural- era una vía abierta de tránsito. La historia que cuenta Carmen Boullosa sucede una década después de la anexión de Texas a Estados Unidos y de la declaración del río Bravo como límite oficial del estado texano.
} 
aquel que es ajeno: las palabras cobran nuevos matices sujetas a la imposición de una ideología que las corrompe.

La acción que detona la diégesis es la confrontación del acaudalado Juan Nepomuceno Cortina contra el beodo sheriff Shears. Después de que en una plaza pública este último golpeara al viejo vaquero, Lázaro Rueda, Nepomuceno se interpone para detener la agresión: “-Ya cállate, grasiento pelado. Las dice en inglés, menos la última, Shut up, greaser pelado" (p. 17). ${ }^{3}$ El ofendido es Cortina. La frase detiene el curso del tiempo y capta la atención de los que asisten a la Plaza del Mercado. De pronto, entre los testigos surge la urgencia de contar a otros lo que sucede. Como si emulara la técnica cinematográfica, "cámara al hombro", el narrador sigue de cerca la trayectoria impredecible que traza la emergencia de difundir el rumor. Los diversos personajes que corren, apresurados por ver las reacciones que pueda despertar la frase, nos alejan de la escena principal. Se genera un contrapunto entre la prisa de éstos y la suspensión de las acciones entre Nepomuceno y el sheriff. De pronto, se escucha un disparo que pocos atienden ya ocupados en sus problemas: después de más de 80 páginas sabremos que Nepomuceno ha herido al sheriff, quien será atendido en la casa de los Smith.

La novela está organizada en seis partes: una breve introducción histórica, las dos partes centrales y mayores de la novela, una nota del autor, una coda y, finalmente, los agradecimientos y las aclaraciones de todos los homenajes literarios evidentes e implícitos en la obra. En lo que es la introducción, que puede ser un tipo de prólogo ficcional, "Pequeña nota de un intruso (que se la salte el que quiera)", se explica desde la perspectiva histórica esta compleja realidad social:

[E]n el año 46, la República de Texas se anexó a los americanos, y pasaron a ser un estado más de ellos, la estrella solitaria.

Inmediato Texas argumentó que su frontera llegaba hasta el Río Bravo.

Ya se sabe lo que siguió, nos invadieron los americanos. (p.12)

\footnotetext{
${ }^{3}$ Cursiva en el original.
} 
Ubicado en un presente contemporáneo al lector, el "intruso" cuenta en retrospectiva y con una clara antipatía contra los norteamericanos, los antecedentes de aquel 1859. El prólogo presenta las normas del universo ficcional al que se enfrentará el lector. Por un lado, expone el contexto histórico, por el otro y lo más importante, anticipa el punto de vista y el sistema de valores que predominará en la novela en el plural "nosotros". El narrador "intruso", al igual que el "nosotros" del narrador de la novela, representa la voz colectiva de los vencidos, los mexicanos. También destaca el guiño hacia el discurso oral popular reflejado en la entonación, el ritmo cacofónico del lenguaje cotidiano y los modos informales, advertidos desde el intertítulo ("que se la salte el que quiera"). Es decir, Boullosa al tratar el relato de un héroe que tuvo un gran protagonismo entre los imaginarios populares de Texas y Tamaulipas al concluir el siglo XIX, se apoya en la vitalidad de este discurso. Así, trae al presente la figura olvidada de Cortina dentro de un marco lingüístico similar al que lo configuró. Más que evidenciar las fuentes documentales que sustentan la investigación exhaustiva de la autora (como así lo hace Ignacio Solares con su protagonista Bernardo Reyes), Boullosa enfatiza el papel de la tradición oral como medio de acceso al pasado y como el medio que da forma al conocimiento de un yo colectivo. Así, la imagen de Cortina se configura lo mismo que su historia y la de los que habitan Bruneville y Matasánchez, fragmentaria y contradictoria. Además, ya en el interior del desarrollo de la trama, en coherencia con esta búsqueda por la sabiduría popular, la novela alude a la topografía, los conflictos sociales y los personajes típicos de un género cinematográfico identificado con la cultura popular de los Estados Unidos: el western, producido y difundido por Hollywood en los años 60 y 70 del siglo XX. ¿Qué resulta de la combinación de la tradición oral, el western norteamericano y el género de la novela histórica?

La preferencia de la autora por un lenguaje informal, cotidiano, en lugar del lenguaje estandarizado del discurso historiográfico, orienta tanto la forma como los temas de la narración. Es decir, determina el "qué" contar y el "cómo" hacerlo. Nos detenemos en el segundo aspecto. Narrada desde el presente figurado de la narración y no en tiempo pretérito, la obra se aleja de las convenciones de una voz narrativa heterodiegética e impersonal (con pretensiones de objetividad). 
El discurso coloquial y cotidiano torna verosímil la organización hasta cierto punto caótica de la información narrativa. El narrador, aunque omnisciente, proyecta una subjetividad cargada de prejuicios que asume como certeros sobre la realidad, el otro y el pasado. Sin embargo, esta misma subjetividad matiza la imposición de sus aseveraciones. Con respecto a la concepción del tiempo, cabe señalar que la informalidad del discurso libera el relato de una noción teleológica y causal de la narración y, por lo tanto, de la manera de entender y representar el tiempo narrativo. Así, las acciones suceden en un tiempo que puede ser interrumpido, circular, ralentizado, etc. Además, en el relato caben los tiempos inasibles de los sueños, las fantasías, los recuerdos y las alucinaciones previas a la muerte. La flexibilidad temporal reformula las nociones y los límites que distinguen al presente, pasado y futuro. Todo parece simultáneo y yuxtapuesto.

La informalidad y el "nosotros" desde el que se narra influye, según advertíamos, en el "qué" contar. El discurso informal es entendido como un medio abierto a la diversidad de voces e historias personales que convencionalmente no cabrían en una Historia con mayúscula. Esto es, contempla los relatos íntimos-familiares dignos de ser narrados al lado de los hechos que trascienden al "gran" relato nacional. Boullosa cuenta el levantamiento civil de Juan Nepomuceno al mismo tiempo que habla de todos los habitantes de Bruneville y Matasánchez (terratenientes, gobernadores, esclavos, distintos grupos étnicos, mestizos vagabundos, niños, etc.), incluyendo objetos, fauna y la transformación del paisaje, lo que da singularidad al espacio donde se desarrolla la historia, pues constantemente señala el aumento de la vaquería y el exterminio del búfalo. En efecto, de los recursos más notables de la novela, destaca la ilusión del desplazamiento continuo de los pobladores y su relación en tensión con el paisaje. La multiculturalidad cobra relieve sobre la imposición de un discurso que defiende una homogeneidad racial e ideológica.

En las primeras páginas se encuentran, por ejemplo, a los trabajadores de una larga lista de distintos oficios: Sharp, el carnicero; Alitas, el pollero; Oscar, el vendedor de pan; el fotógrafo francés o belga, Le Plange; Olga, la lavandera; La Grande, que administra una fonda y un hotel; Salustio, vendedor de jabones y velas y Peter Hat, austriaco dueño de una tienda de sombreros. 
Están otros personajes, sinécdoque de su comunidad: Pérez, el comanchero; los hermanos Agua Fuerte y Caída Azul, apaches lipanes; el único negro adinerado, Tim Black. También se mencionan a las comunidades de apaches, comanches, cherokees, caddos; vaqueros, alemanes, y, un grupo particular que refleja la postura de género de la autora, las habitantes del rancho Las Tías, mujeres que viven en los márgenes de La Gran Pradería, todavía territorio texano, "usan el lazo, le saben al revólver, detestan el cultivo y odian vivir entre cuatro paredes" (p.70). La gran cantidad de personajes, individualizados a través de su historia y su voz, configura un microcosmos social que alude a las narrativas de largo aliento del siglo XIX de intención realista y estética costumbrista. EI espacio adquiere una personalidad en la diversidad de sus habitantes. Éstos, a su vez, se descubren y reconocen en el espacio que también modifican y construyen de acuerdo al cambio de sus hábitos, costumbres y creencias. Para los propósitos estéticos y narrativos de la novela, una de las funciones principales de esta heterogénea colectividad es su participación en la generación, propagación y transformación del rumor. Otro de sus papeles será la planeación de la sublevación contra las injusticias cometidas por las autoridades norteamericanas, en la que participará el grupo clandestino de Las Águilas.

La ofensa a Nepomuceno al Ilamarlo "pelado", desatará la rebelión de los mexicanos (narrada en la segunda parte de la novela). La ofensa trasciende no tanto por lo que en sí mismo significa el vocablo: "el que no posee bienes o no tienen una posición económica o social apreciable". Sino porque la expresión, en el contexto, implica un cambio valorativo; una nueva forma de evaluar al "otro", el que no es norteamericano. El detonante del movimiento social, entonces, tiene su explicación en la verosimilitud de un universo de ficción literaria: el cambio en la apreciación y valor de un vocablo cotidiano, inocuo, intrascendente.

Este nuevo juicio de valor revela el desajuste entre la palabra y su referente. Juan Nepomuceno Cortina es "el hijo de doña Estefanía, nieto y bisnieto de los dueños de los más de mil acres de tierra de Espíritu Santo, donde están Bruneville" (pp. 17, 18). En oposición, el sheriff es un norteamericano, "carpinteritos venido a más, sheriff de chiripa" (sic) (p.18). En la descripción de 
ambos personajes, el narrador refracta las voces de la colectividad que simpatiza con el mexicano. La diferencia económica y social explicita la falacia de la ofensa. Los habitantes de Bruneville son testigos del nacimiento de "un mundo al revés"; del ingreso de lo mexicano en una "otredad" que lo degrada. La nacionalidad de Cortina es lo que incita la grosería de Sharp: su ascendencia mexicana es evaluada desde un sistema negativo recién instaurado y legitimado una década atrás, en el tratado de 1848, mencionado en el prólogo. La sorpresa de la ofensa es más dramática si atendemos a la descripción de los personajes:

Inmóviles, frente a frente, el sheriff Shears medio encorvado, los cabellos delgados empegostados por el sudor, la cara descompuesta de la ira, el cañón de la pistola (con cuya culata golpeara a Lázaro Rueda) agarrado por sus dedos nudosos, los ojos bizcos barriendo en dos puntos el suelo [...] Nepomuceno erguido, alto, los brillantes ojos clavados directo, el pantalón de montar de buena tela (no cualquier cosa: casimir escocés) mandado a cortar a su medida con el mejor sastre de Puebla, el saco de vestir muy formal (sastre de Nueva Orleans). (pp. 79,80)

Al estilo western el narrador fragmenta la figura de ambos: enfatiza el descuido de la ropa y el físico desagradable del sheriff, alusión a la representación del vaquero en las películas del viejo oeste. En contraparte, pone en relieve la elegancia y gallardía de Nepomuceno, el vaquero mexicano, ya una figura inexistente en el imaginario colectivo nacional. La confrontación, como un espejo invertido, muestra claramente lo descabellado de la ofensa y el racismo implícito que detonará, de distintas formas, un discurso del odio sobre el otro y "lo" otro. En este punto la novela identifica el comienzo de la leyenda de Juan Nepomuceno Cortina.

El rumor que se reitera como una repetición mecánica de una frase, genera un texto fragmentario, abierto a las digresiones y a la propia transformación del suceso principal. La escena del duelo se vuelve un acto inacabado y al mismo tiempo, inestable, heterogéneo, vital e impredecible en sus consecuencias. El duelo motiva la reorganización de la población en nuevas 
alianzas o nuevas enemistades. En silencio, se producen las primeras muertes por azar o por venganza.

La segunda parte de la novela, más breve que la primera, se titula "(seis semanas después)", entre paréntesis como una cortinilla del cine mudo. Este capítulo relata precisamente los pormenores de los dos ataques a Bruneville y la captura final de Nepomuceno por federales mexicanos para enviarlo a la cárcel de Tlatelolco. En torno a la acción principal de esta segunda sección de la obra, se desarrollan dos historias paralelas: una, que refiere los efectos indirectos, como en una reacción en cadena, de la rebelión de los mexicanos. La otra se construirá a partir de las citas tomadas directamente de artículos de periódico y los informes de la época, según refiere el propio narrador. Se pasa de la oralidad al discurso periodístico. Las citas y fragmentos parafraseados aportan la perspectiva de los norteamericanos para subrayar la manipulación de la información y la distorsión de los hechos. Con ello, se generan versiones desfavorables sobre la imagen, la ética y la moral de los mexicanos y, por supuesto, de Cortina, su "Amenaza Roja". El ejemplo más evidente de esta confrontación de perspectivas es la recreación que harán los medios norteamericanos de la muerte de Caroline Smith y su esclava asinai, Rayo de Luna. ${ }^{4}$

La fragmentariedad de la novela tiene la intención de generar la ilusión de simultaneidad y de un presente caótico, emulando la confusión de la revuelta social. Por otra parte, las múltiples historias que se alternan con el acontecimiento principal de esta segunda parte y los fragmentos citados de las proclamas de Nepomuceno, contestan las versiones denigrantes de los

\footnotetext{
${ }^{4}$ En la versión del narrador, Rayo de Luna es perseguida en un juego de cortejo por el nepomucenista Ludovico. La esclava, corriendo divertida por los pasillos de la casa de los Smith, entra al patio donde todavía se encuentra convaleciente Shearp. Con la vista nublada y temeroso por la posible revancha de Nepomuceno, el sheriff dispara sin identificar el blanco: Rayo de Luna cae muerta. Asustado, el sheriff tira la pistola y grita culpando a Ludovico: "iEl greaser mató a la comancheeeieee!" (p. 310). Caroline, al atestiguar el asesinato de su esclava, pierde la razón, toma la pistola y se suicida. En la confusión, en las calles se escuchan los gritos anónimos: "-iUno de Nepomuceno asesinó a Rayo de Luna! -Otro se echó a Caroline, la de los Smith! -iEstán violando mujeres, los greaser!” (p. 313). En los periódicos, con una clara tendencia a desprestigiar el movimiento de los sublevados, la noticia será referida de la siguiente forma: "después de haber apuñalado y disparado incluso a los cuerpos muertos de la hija del honorable mister Smith, Caroline, así como de tres de nuestros hombres..." (p. 332). La nota concluye difamando a los rebeldes: "Sus hombres no viven sino de robar caballos -ha sido su industria desde siempre-. Han escapado de la justicia echando mano de testigos falsos'”' (p. 332).
} 
norteamericanos. De esta manera, mientras la lucha de nuestro protagonista tiene un motivo político, en la recreación que harán los norteamericanos, esta sólo se justifica como un acto criminal cuyo autor intelectual es un ladrón de ganado, un impresentable iletrado que apodarán "The Robber" o "The Bandito" (p. 334). Esta versión deslegitima la rebelión de los nuevos ciudadanos estadounidenses (otrora mexicanos) por la defensa de sus derechos económicos, sociales y de igualdad racial. A su vez, la leyenda popular tan contradictoria en su origen incide de forma directa en la construcción de un imaginario peyorativo sobre lo mexicano y su identidad.

El personaje de Nepomuceno es el medio para acercarnos a un pasado poco difundido de la historia nacional y, a la vez, simboliza los conflictos raciales, culturales y étnicos que a la declaración oficial de los límites fronterizos sólo legitimó los odios e inclinó la balanza hacia el nuevo colonizador. De esta forma, para Carmen Boullosa, hablar de la historia de Texas es incorporar el origen de una multiculturalidad borrada en el arte norteamericano, particularmente en su cine popular. Al mismo tiempo, la autora subraya la frontera como un espacio de tránsito cuyas historias y héroes, más que separar, unen a ambos países.

\section{Bernardo Reyes, un personaje trágico}

En el año del 2013, centenario del cuartelazo contra el presidente Francisco I. Madero, Ignacio Solares publicó Un sueño de Bernardo Reyes, ${ }^{5}$ una breve novela sobre uno de los generales más leales a Porfirio Díaz y el más probable sucesor presidencial del dictador en los albores de 1908. Similar a su novela, Madero, el otro (1989), la obra inicia narrando el declive del protagonista: buscado por sedición contra Madero, después de vagar diez días en el desierto y ya abandonado por los soldados que lo acompañaban, la víspera de la Navidad de 1911 Reyes se entrega en la cárcel de Laredo. La rendición "tragicómica”, según califica el narrador, advierte al lector el tono fatalista y dramático de la historia que escribe Ignacio Solares. En principio, el énfasis en la derrota moral de su personaje cuestiona la valoración generalizada del histórico Bernardo Reyes como el

\footnotetext{
${ }^{5}$ En el presente trabajo se consultó la edición de Alfaguara publicada en 2013. Las páginas se pondrán entre paréntesis.
} 
villano de la historia nacional en contrapunto con la imagen de Francisco I. Madero, quien es considerado el mártir de la Revolución Mexicana. Mas, no es un discurso del fracaso y la derrota lo que configura la personalidad y la psicología del personaje literario.

Ignacio Solares pone en diálogo dos fuentes discursivas que combinan lo público y lo privado: la historiografía más destacada sobre el tema que comprende a autores como Martín Luis Guzmán o la investigación de Antonio Saborit; y los escritos que Rodolfo y Alfonso Reyes dedicaron a su padre: De mi vida. Memorias políticas (1899-1913) y Oración del 9 de febrero (1930), respectivamente. La figura del gobernador de Nuevo León, héroe y/o villano, se mezcla con una imagen de otras complejidades basada en las emociones y los recuerdos de sus hijos. En la novela, la figura histórica oscila entre el deber patriótico y el deber filial, entre el gobernador y militar incorruptible y el padre admirado. De esta forma, el lector no encontrará revelaciones o datos históricos novedosos sobre Bernardo Reyes o sobre los acontecimientos que desencadenaron la Decena trágica, pues el autor se apega a los datos verificados por la historiografía. Sin embargo, las memorias de Rodolfo Reyes y, sobre todo, la Oración del 9 de febrero, alejan la figura del gobernador de la épica nacional y lo desplazan hacia un contexto más íntimo y nostálgico que es aprovechado por Solares.

En la carta, Alfonso Reyes señala a su padre como un romántico tardío, lector apasionado de El diablo mundo y amigo del poeta nicaragüense, Rubén Darío. Un tipo de Quijote por su físico y sus valores éticos. Para Reyes, su padre era un fiel creyente de la materialidad de las palabras, un lector riguroso que se acercaba a la literatura con severidad, "Entonces entendí que él había vivido las palabras, que había ejercido su poesía con la vida, que era todo él como un poema en movimiento, un poema romántico de que hubiera sido a la vez autor y actor" (1930, p.38). De la referencia a las fiebres recurrentes provocadas por el paludismo contraído en alguna campaña (dato que también refiere Rodolfo Reyes) y de la trascendencia casi mística atribuida por el general a las palabras y a la literatura, Ignacio Solares dota de un carácter premonitorio y verdadero a las pesadillas palúdicas de su personaje. Según la novela, en uno de aquellos sueños tortuosos, Bernardo Reyes advierte la 
proximidad de una guerra civil ocasionada por la debilidad del carácter del presidente Madero. La certeza de una crisis social explica la urgencia y la exaltada pasión del general por defender a la patria. En la novela, lo que detona el movimiento civil es una pesadilla, tópico propiamente literario: la experiencia onírica se asume como un hecho vital desencadenante de la fatalidad de su protagonista. Así, el narrador configura en Reyes un personaje un tanto quijotesco y un tanto personaje tragicómico shakesperiano, que románticamente como un "poseído" (p.29) se aventura a la rebelión frente a las puertas de Palacio Nacional para, estoicamente, morir acribillado:

-Apártese de esta puerta, Lauro. Nada podrá impedir que pase yo por ella. Es a Madero a quien venimos a derrocar para salvar a la patria.

Y Reyes continuó su avance, sonámbulo. Casi echó el caballo encima de las ametralladoras. Rodolfo, que iba detrás, le gritó:

-iTe matan!

-iPero no por la espalda!

Ésa fue su última frase, pareció la orden de fuego que prendió la mecha. (p. 30)

Centrado en las vicisitudes de un solo individuo (flaquezas, errores, contradicciones), el autor de Nen, la inútil remarca los efectos en cadena de las decisiones de su protagonista en el devenir histórico de la sociedad mexicana. El personaje ficcional de Reyes, tan concentrado en sí mismo, en su obediencia a Porfirio Díaz y en los defectos de Madero como presidente, no advierte que con sus actos apresura la catástrofe que porfiadamente intenta evitar: a su muerte provocará el cuartelazo contra Madero, Victoriano Huerta asumirá la presidencia y resurgirá con mayor fuerza el movimiento revolucionario. Lo onírico trasciende la realidad íntima del personaje para traspasar al devenir histórico de una colectividad.

Al lado de la versión anterior, Ignacio Solares reconoce otra posibilidad para explicar la locura de su protagonista: la renuncia de Bernardo Reyes a ser candidato por la presidencia ante la imposición de una nueva reelección del dictador: "Todo parecía indicar -era lo más sensato- que Reyes sería elegido candidato presidencial para las próximas elecciones. [...] Pero una reunión entre 
Díaz y Reyes impidió lo que parecía inminente" (p. 99). El gobernador de Nuevo León, a pesar de lo cuestionable de su decisión entre los numerosos políticos y civiles ya identificados como reyistas, acepta esperar seis años más para postularse como candidato de oposición. Aquel 1908, Reyes traspasa el umbral hacia la borradura de su trayectoria política y militar; su vida parece desorientarse:

Él, que no se enfrentó a don Porfirio cuando debía haberlo hecho [...], que regresó al país cuando ya no tenía sentido, que se sublevó contra Madero en el momento menos propicio, que se entregó en Linares cuando su rendición no significaba nada para nadie [...] Cuánto tuvo que odiar a Madero y su debilidad para actuar contra sí mismo en forma tan absurda". (p. 21)

El adverbio anuncia un problema de desface temporal: Reyes salió del curso lógico de su propio relato; contradictorio, se marginó de la historia nacional y de la memoria colectiva. ¿Cómo recuperar el sentido de la vida de Reyes? Ignacio Solares en el cruce de la historiografía y la imagen nostálgico-literaria de Alfonso Reyes, propone una tercera vía para comprender y configurar a su personaje: en el instante previo a su muerte, ya acribillado, el general descubre que su destino era morir para rememorar y reconocer, entre la danza caleidoscópica de sus recuerdos, la pesadilla que lo llevaría inevitablemente a caer frente a Palacio Nacional:

Supo que había nacido para esto. Que toda su vida se reducía, ahora, a la culminación de este momento final [...]

Llegaban en el recuerdo a encontrar recién su destino.

Recordaba. La memoria no morirá aunque su cuerpo muriera. (p. 37)

La memoria como habilidad y como medio para recuperar los recuerdos tiene una función estructurante de la diégesis de la novela. Acudir a la memoria no sólo como tema sino como un recurso para organizar lo narrado, sugiere un manejo de la temporalidad distinto a la noción teleológica implicada en el tiempo lineal y progresivo. Por otra parte, la insistencia del narrador 
sobre la pesadilla de Bernardo Reyes desplaza las explicaciones históricas o el azar como principio causal en la vida del gobernador. Así, el sueño contribuye a crear una atmósfera onírica cuyas libres asociaciones de las distintas imágenes del pasado se sustentan en una lógica surrealista que conduce al desenlace fatal. La novela propone que Reyes nunca perdió el cauce de su vida, por el contrario, desde siempre siguió el camino trazado hacia su destino, un camino que pertenecía realmente a otro orden temporal.

El acto de rememorar de Bernardo Reyes detona una búsqueda en direcciones impredecibles de los recuerdos. Para reconocerlos, entre la heterogeneidad de materiales que componen la novela, el narrador los vuelve explícitos al inicio de algunos párrafos y capítulos con el verbo "recordó". Sin embargo, en la narración no se encuentran aislados los episodios de aquel pasado recuperado sino que éste se combina con las citas de las investigaciones historiográficas y los fragmentos tomados de las memorias de Rodolfo Reyes y de la carta de Alfonso Reyes. Es decir, el narrador sigue desde una distancia cognitiva y temporal privilegiada a su protagonista. A través del discurso indirecto, la voz del general se refracta en las apreciaciones y valoraciones de este narrador, pero es notable el papel predominante de la voz narrativa como mediador entre la narración y lo narrado.

En el anuncio "recordó" pone en relieve tanto la preeminencia del narrador como la advertencia sobre la naturaleza de aquello que está siendo narrado. Cabe señalar que en el acto de rememoración se insertan citas entrecomilladas que remiten al formato de la investigación académica, pues los fragmentos referidos confirman o completan la percepción y los datos narrados-recordados. A diferencia de la novela de Boullosa, donde la oralidad tiene un papel protagónico, la novela de Solares remarca sus fuentes textuales. La obra de este último oscila entre las normas de la ficción literaria y la insistencia por evidenciar el sustento verificable de lo narrado. Sin embargo, la referencia a las investigaciones de los historiadores o de los documentos no pretende legitimar o validar los recuerdos o percepciones del protagonista. Este recurso, de hecho, no busca asimilar el tono solemne y severo de lo oficial o verificable, sino que subraya la 
construcción del pasado como un crucero en el que confluyen distintas voces y temporalidades; un pasado cuyo relato depende de la historia personal, la historiografía y la historia colectiva.

La heterogeneidad de los materiales y su confluencia en el mismo espacio narrativo también influye en la manera de entender y representar el tiempo en la novela. Esta heterogeneidad discursiva crea en el lector la ilusión de ocupar de forma simultánea el presente, pasado y futuro. El acto de rememorar del protagonista, los documentos citados y la narración de la voz narrativa, ocasiona un constante desplazamiento de perspectivas y percepciones espaciotemporales. Por supuesto, en un sentido convencional, al hablar de memoria reconocemos su inherencia con el tiempo pasado, sin embargo, la novela relativiza esta certeza y propone las tres temporalidades como nociones abiertas, flexibles, que adquieren un sentido espaciotemporal concreto de acuerdo a la ubicación de quien realiza en cada momento el acto de enunciación:

-¿A qué se debe su visita tan intempestiva y tempranera, general?- le preguntó [a Victoriano Huerta] con amabilidad, pero sin ofrecerle algo de beber.

A pesar de que había cumplido con eficiencia algunas de las misiones que se le habían encomendado hasta entonces, Reyes siempre guardaba cierta desconfianza hacia su subalterno ("Le encargó las campañas pacificadoras de Guerrero y Yucatán, tolerándole sus excesos y su politiquería", cuenta Javier Garciadiego), esa cierta desconfianza, que confirmó aquella mañana. "No me gusta su aspecto siniestro, pero me ha sido un hombre útil”, le había dicho poco antes a su hijo Rodolfo.

-Señor ministro, yo creo que el general Díaz no puede ni debe reelegirse aseveró con firmeza Huerta. (pp. 81, 82)

En el fragmento anterior puede notarse con claridad la heterogeneidad de los materiales que conforman la narración. El narrador, que asume un papel omnisciente y heterogéneo, deja en suspenso el diálogo para exponer la desconfianza de Reyes sobre la figura de Huerta. Por supuesto, el guion largo que anuncia el inicio de la conversación trae al presente aquella escena que después 
el narrador nos recuerda que forma parte del pasado. El paréntesis ilustra en voz del historiador Javier Garciadiego la información generalizada del narrador. De esta forma, la cita nos traslada hacia un pasado más remoto para entender la tensa relación entre ambos personajes. El diálogo, como cierre de la cita, coloca al lector de nuevo en un presente vital de la comunicación que no deja de pertenecer al pasado. Por otro lado, el capítulo al que pertenece el fragmento, "XIII. Un ave agorera", revela lo que para el presente de la charla será el futuro inexorable, pues Huerta efectivamente será, a la muerte de Bernardo Reyes, el usurpador de la presidencia de Madero. En el fragmento citado se ejemplifica precisamente el lugar privilegiado del narrador, quien, desde los intertítulos y ciertos comentarios, explicita su ubicación en un presente remoto al pasado relatado.

La narración, además, hace énfasis en la frágil separación entre lo que fue y lo que pudo haber sido. O planteado de otra manera, entre lo que efectivamente pasó y lo que pudo evitarse. Más que la sensación tranquilizadora de un pasado idílico o la posibilidad de un futuro utópico o alterno, Ignacio Solares explora el determinismo histórico como una imposición casi mística sobre el protagonista de su novela. La voz narrativa, ubicada en un presente alejado de aquellos hechos, plantea en constantes preguntas retóricas un futuro interrumpido; el vacío de un mundo posible, el "como si", de la violencia y el caos atroz que pudo evitarse. Las dudas generan una tensa relación entre el pasado, concluido y cerrado, y la potencialidad de un futuro que no fue. El narrador provoca al lector con preguntas que finalmente no tienen solución aparente en el tejido de la trama: “¿Hubiera entonces evitado, si llega al poder, la guerra civil que provocó, sin remedio, la presidencia de Victoriano Huerta?" (p. 33). Esta sensación de impotencia se intensifica al ser los recuerdos seleccionados de Bernardo Reyes el centro y punto de fuga de la narración. El personaje es configurado como un centro gravitacional de los tres tiempos: pertenece al pasado del régimen porfirista, es el presente de la agonía que simboliza el desencanto por la política de Madero y es también un vacío, el tiempo hipotético de aquello que no pudo ser o que fue imposible evitar. El final de la novela es revelador en este sentido, pues agónico recordó, nos señala la voz narrativa, aquella extraña pesadilla de sus fiebres palúdicas. 
La gran tragedia del Bernardo Reyes literario es precisamente el descubrimiento final, previo a su muerte, en el que descubre el origen del sentido de su vida. El hilo de la vida de Reyes une sus extremos que es ese instante previo a la explosión y búsqueda de sus recuerdos.

A diferencia de la novela de Carmen Boullosa, las voces y la vida de los habitantes de aquel México de transición entre el XIX y XX no tienen eco en la novela de Solares. Bernardo Reyes como el centro de la diégesis, es el medio a través del que conocemos tanto a Madero como a Porfirio Díaz. ¿Qué trae al presente de su experiencia con ambos personajes protagónicos del pasado? La figura de Madero aparece como un corchete en la vida del protagonista: él lo llevó de la cárcel de Laredo a la de Tlatelolco, en la Ciudad de México para, finalmente, dejarlo libre. En las pocas escenas donde se aborda la figura de Madero, la novela configura la imagen de un hombre benevolente de espíritu democrático adelantado a su tiempo. Para Alfonso Reyes (1930, p. 16,17), el desencuentro entre Madero y su padre sólo puede explicarse de la siguiente manera: "[d]os grandes almas se enfrentaban, y acaso se atraían a través de no sé qué estelares distancias. Una toda fuego y bravura y otra toda sencillez y candor. Cada cual cumplía su triste gravitación". En las novelas de Ignacio Solares, cada uno será víctima de su propio oráculo.

En el caso de Porfirio Díaz, la novela remarca los aciertos de su mandato y deja entrever algunos detalles de su infancia. Sin embargo, el narrador delega al propio Porfirio Díaz, en diálogo con su ministro de guerra, Bernardo Reyes, la enumeración de los avances en transporte, telecomunicaciones y el progresivo desarrollo civilizatorio del país. En algún momento, el narrador filtra uno de los elogios más ingeniosos hechos hacia el dictador: “¿Recordó Reyes al saludarlo que uno de los autores más prestigiados en aquellos momentos, León Tolstói, lo llamó 'prodigio de la naturaleza'?" (p. 99).

De forma paralela, la narración insiste en la moral intachable de Bernardo Reyes, en la coherencia de su pensamiento y sus acciones. La severidad de su vida se corresponde con el poder que infiere a sus palabras. Para completar este retrato elogioso sobre nuestro protagonista, el narrador cita a la historiadora Josefina González: “por primera vez en su historia, la nación tenía un 
verdadero ministro de Guerra, inteligente, progresista, organizador, honrado a carta cabal en sus manejos para distribuir con limpieza su presupuesto" (p. 80). Es inevitable hacer el vínculo entre la imagen del general y el presente en el que se publica la novela, pues la cita retrata precisamente aquello de lo que adolece el presente del país en el año del 2013: de liderazgo presidencial y de organización y compromiso militar.

\section{A manera de conclusión}

Carmen Boullosa e Ignacio Solares relacionan la noción del tiempo con los procesos impredecibles de la memoria. Fenómeno representado como una red que se construye paulatinamente en la oscilación constante ( $y$ a veces difusa) entre la experiencia colectiva y la individual. Con el movimiento pendular, las novelas parecen borrar los límites convencionales entre los tres tiempos con los que asimilamos y relatamos nuestro actuar en el mundo: el presente, pasado y futuro. De este modo, ambas novelas explicitan un fenómeno que coincide con las preocupaciones que la teórica Diana González (2015, p. 168) identifica en el arte argentino contemporáneo: visibilizar que habitamos "una temporalidad múltiple en la que pasado-presente-futuro no se hallan separados mediante cesuras que marcan etapas. Nuestros recuerdos, experiencias y expectativas forman continuamente parte de nosotros, nos constituyen y suceden simultáneamente". Este planteamiento aporta un tratamiento interesante en la relación de los narradores con los hechos contados y con el entramado que cada uno hará de su relato. En Solares, la cercanía entre la rememoración y el sueño entendidos ambos como espacios individuales de temporalidad relativa dota de un misticismo casi esotérico al fatalismo y la tragedia de Bernardo Reyes. En Carmen Boullosa, la memoria en su relación con la oralidad, al margen de la historia oficial, dota de una estructura "caótica", de los detalles y lo cotidiano, para proyectar nuevos valores como pilares de una heroicidad nacional perdida.

EI XIX y los albores del XX, es el lugar de la búsqueda, más que de un pasado nostálgico, de una esperanza para pensar en el futuro. De esta forma, abordar dos personajes históricos poco 
nombrados (incluso olvidados) en la historia nacional, a mi parecer, responde a la preeminencia de los discursos y la visibilidad que ha cobrado la mal llamada "cultura" del narcotráfico. En los medios masivos de comunicación, es visible la popularidad de los nuevos héroes y temáticas vinculadas con el crimen organizado. En la música, en el cine y en las series, se repiten nombres y sucesos que ensalzan la vida de anónimos y conocidos criminales relacionados con el tráfico de drogas, la corrupción y su complicidad o confrontación con las fuerzas federales. En este sentido, las novelas de Boullosa y Solares refieren las crisis de un pasado más o menos próximo para subrayar los valores, la ética y los compromisos en la defensa de ideales y búsquedas de liberación e independencia que justifican la violencia imperante de aquellas épocas. El valor de la amistad, la lealtad y la coherencia de los personajes sobre sus propias luchas personales (que se tornan colectivas) parecen proponer un retrato idealizado del pasado; sin embargo, en el contexto actual, en el que la historia se construye y destruye cada día, el tono conservador de ambas obras trasciende una visión simplista o moralina.

Diana González Martínez (2015, p. 161), en su libro, Emancipación, plenitud y memoria, nos dice que es posible emanciparse cuando se "aprende a vivir realmente en la multiplicidad, aceptando la diferencia, manteniendo al otro como otro, aunque parte de nosotros mismos". Las novelas, fincadas en la confluencia de las experiencias y los recuerdos personales con la memoria colectiva, parecen abonar a este objetivo: emancipar nuestros imaginarios y nuestra interpretación del pasado. Cada autor intenta responder no sólo al olvido de un personaje sino a la usurpación de una memoria que es mucho más digna y ejemplar tanto del mexicano como de su relación con el otro. En pleno 2018, con el país vecino del norte dirigido por un presidente texano, es urgente visibilizar la natural relación, por antigua, de intercambio económico, social y cultural con los Estados Unidos. Al mismo tiempo, pensando en una presidencia saliente y un contexto de migración imponente, es necesario repensar las nuevas formas de colonización que deben de ser desautomatizadas. 


\section{Referencias:}

Boullosa, C. (2013). Texas. La Gran Ladronería en el Lejano Norte. México: Alfaguara.

Erll, A. (2012). Memoria colectiva y culturas del recuerdo. Estudio introductorio. Johanna Córdoba, Tatjana Louis (tradd.) Bogotá, Colombia: Universidad de los Andes, Facultad de Ciencias Sociales; Uniandes.

González, D. (2015). Emancipación, plenitud y memoria: modos de percepción y acción a través del arte. Madrid: Iberoamericana; Vervuert.

Solares, I. (2013). Un sueño de Bernardo Reyes. México: Alfaguara. 